\title{
Phytochemicals for the treatment of COVID-19
}

\author{
Erica Españo, Jiyeon Kim, Kiho Lee, \\ and Jeong-Ki Kim ${ }^{\star}$ \\ Department of Pharmacy, Korea University College of Pharmacy, \\ Sejong 30019, Republic of Korea \\ (Received Sep 7, 2021 / Revised Oct 20, 2021 / Accepted Oct 20, 2021)
}

The coronavirus disease 2019 (COVID-19) pandemic has underscored the lack of approved drugs against acute viral diseases. Plants are considered inexhaustible sources of drugs for several diseases and clinical conditions, but plant-derived compounds have seen little success in the field of antivirals. Here, we present the case for the use of compounds from vascular plants, including alkaloids, flavonoids, polyphenols, and tannins, as antivirals, particularly for the treatment of COVID-19. We review current evidence for the use of these phytochemicals against SARS-CoV-2 infection and present their potential targets in the SARS-CoV-2 replication cycle.

Keywords: antivirals, alkaloids, coronaviruses, COVID-19, flavonoids, phytochemicals, natural products, SARS-CoV-2

\section{Introduction}

The coronavirus disease 2019 (COVID-19) caused by the severe acute respiratory syndrome coronavirus 2 (SARS-CoV2) has infected over 218 million and killed over 5.2 million people (WHO, 2020). The COVID-19 pandemic has underscored the limitations of the current pool of approved antivirals and has emphasized the need for further discovery and development of therapeutic and prophylactic agents for acute viral diseases. Plants have been utilized throughout human history for a variety of ailments and are considered inexhaustible sources of novel pharmacologically active compounds. Phytochemicals and their derivatives have already been approved for non-viral disease states. Among these compounds are paclitaxel from the Pacific yew tree (Taxus brevifolia), and vincristine and vinblastine from periwinkle (Catharanthus rosea) for cancer treatment; morphine from opium poppy (Papaver somniferum) and aspirin derived from salicylic acid from the bark of willow trees (Salix spp.) for pain management; and quinine from quina trees (Cinchona spp.) and artemisinin from sweet wormwood (Artemisia annua) for con-

*For correspondence. E-mail: jkfrancis@korea.ac.kr

Copyright (C) 2021, The Microbiological Society of Korea trolling parasitic infections. However, the majority of approved antivirals are synthetic small molecules, and a plant-derived antiviral is yet to be approved (Tompa et al., 2021). Unlike designed synthetic small molecules, plant secondary metabolites have evolved to exhibit biological activity, thereby increasing the likelihood of their interactions with other biological molecules, which is evident in the breadth of pharmacological activity exhibited by phytochemicals (Atanasov et al., 2021). Plant secondary metabolites, especially those that are used as food or as traditional medicine, may also be safer than synthetic molecules. Plants therefore remain rich but underutilized sources of antivirals. Here, we present some of the characterized secondary metabolites from vascular plants that have been observed to inhibit either SARS-CoV-2 replication or SARS-CoV-2 functional components at least in vitro.

\section{Druggable Targets in the SARS-CoV-2 Replication Cycle}

SARS-CoV-2 is a Betacoronavirus under the Coronaviridae family of relatively large positive-sense single-stranded RNA viruses. SARS-CoV-2 particles are spherical, with lipid envelopes surrounding an icosahedral capsid that protects the genomic RNA (around $29.9 \mathrm{~kb}$ ). The $5^{\prime}$ end of the genome encodes 16 nonstructural proteins (NSP1-16), while the $3^{\prime}$ end encodes four structural proteins: spike (S), envelope (E), and membrane $(\mathrm{M})$, and nucleocapsid $(\mathrm{N})$. The homotrimeric glycosylated $\mathrm{S}$ protein is the predominant structure on the $\mathrm{CoV}$ envelope and is central to the $\mathrm{CoV}$ entry process. Each $S$ protein consists of two noncovalently bound subunits: the surface-exposed S1, which contains the receptor-binding domain (RBD), and the transmembrane S2, which facilitates fusion with the host membrane. The infection cycle of SARS$\mathrm{CoV}-2$ is initiated by the interaction of the RBD with angiotensin-converting enzyme 2 (ACE2), the known SARS-CoV2 receptor in humans (Fig. 1) (Yan et al., 2020). Proteolytic cleavage at the S1/S2 interface of the S protein triggers a series of conformational changes that lead to fusion of the viral envelope with the host membrane. SARS-CoV-2 S priming has been found to be dependent on transmembrane serine protease 2 (TMPRSS2) on the host cell surface (Hoffmann et al., 2020); however, in the absence of cell surface proteases, endosomal proteases, such as cathepsins B and L, may also facilitate SARS-CoV-2 S priming, suggesting that SARS-CoV2 enters the host through both direct fusion with the plasma membrane and the endocytic pathway (Ou et al., 2020).

Following fusion, the genomic RNA is uncoated in the cy- 


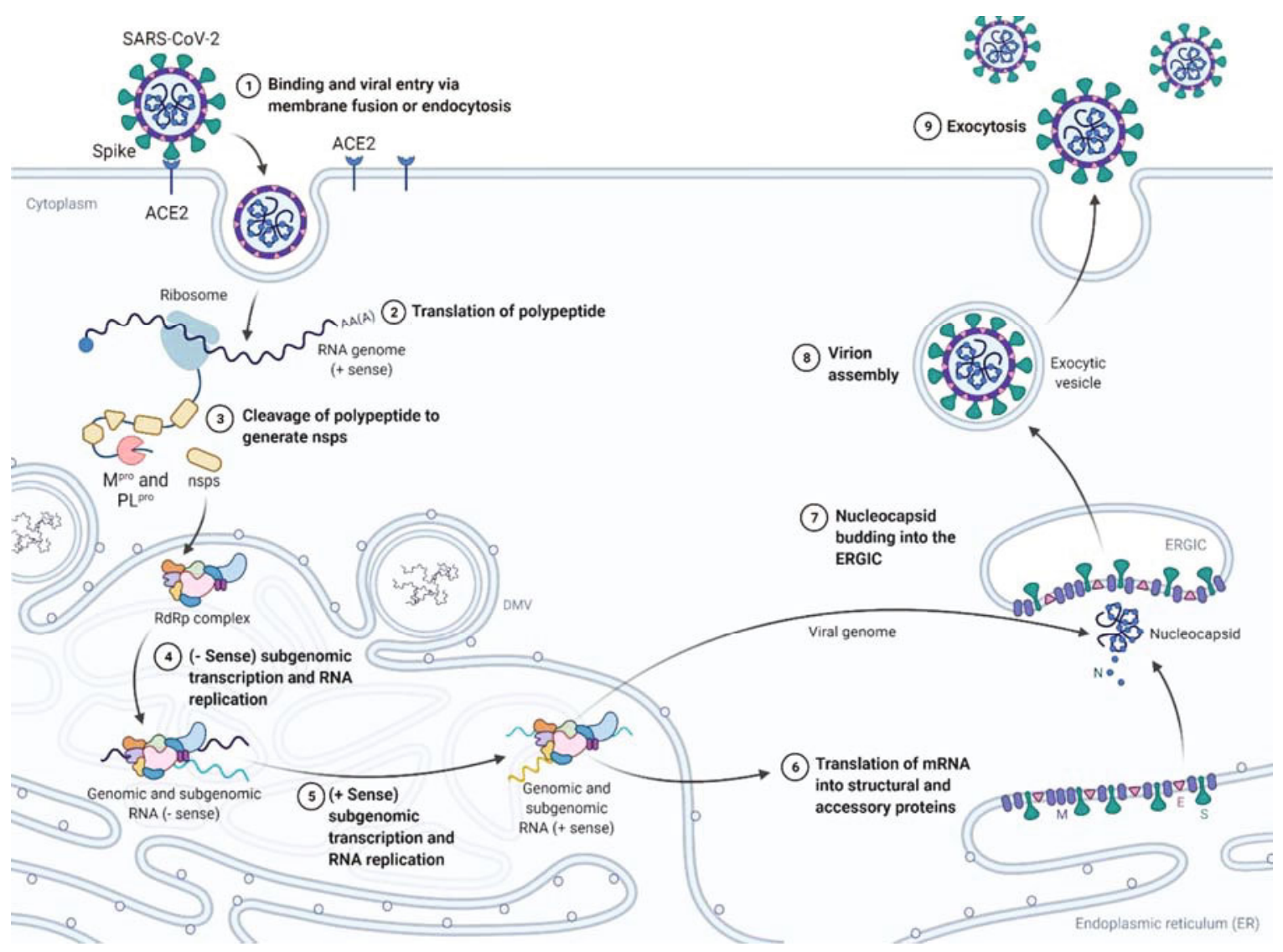

Fig. 1. The infection cycle of severe acute respiratory syndrome coronavirus 2 (SARS-CoV-2). (1) The SARS-CoV-2 spike (S) protein binds human angiotensinconverting enzyme 2 (ACE2) on the cell surface. Following binding, the $S$ protein is cleaved by transmembrane protease, serine 2 and facilitates viral entry. The SARS-CoV-2 particles enter the host through either direct membrane fusion or endocytosis. (2) The SARS-CoV-2 genomic RNA is uncoated into the cytoplasm and is translated into polyproteins. (3) The main protease $\left(\mathrm{M}^{\mathrm{pro}}\right)$ and papain-like protease $\left(\mathrm{PL}^{\mathrm{pro}}\right)$ cleave the translated polypeptides, releasing the nonstructural proteins (nsps), which then assemble into the transcriptional machinery in double-membraned vesicles (DMV). (4 and 5) The RNA-dependentRNA polymerase (RdRp) facilitates subgenomic RNA transcription and replication. (6) SARS-CoV-2 mRNA is translated into structural and accessory proteins in the endoplasmic reticulum. (7 and 8 ) The structural proteins and the nucleocapsid are assembled into the lumen of secretory vesicles through the ER-to-Golgi intermediate compartment (ERGIC). (9) Finally, the assembled SARS-CoV-2 particles exit the cells through exocytosis. Image was created with BioRender.com.

toplasm, making it accessible for primary translation into two polyproteins pp1a (NSP1-11) and pp1ab (NSP1-10, 12-16), which are co-translationally and post-translationally cleaved by the papain-like protease $\left(\mathrm{PL}^{\mathrm{pro}}\right)$ within NSP3 and the main protease $\left(\mathrm{M}^{\mathrm{pro}}\right.$; also known as the $3 \mathrm{C}$-like protease, $\left.3 \mathrm{CL}^{\mathrm{pro}}\right)$ within NSP5 (V'kovski et al., 2021). After proteolytic processing, NSP2-16 assemble to different subcellular localizations and perform their subsequent roles in the SARS-CoV2 replication cycle. NSP2-11 provide cofactors to the viral polymerase and perform supporting functions for viral replication and translation, including the formation of doublemembrane vesicles where replication and translation take place. RNA-related enzymatic functions are attributed to NSP12-16, such as the viral RNA-dependent RNA polymerase (RdRp) activity of NSP12 and the $3^{\prime}-5^{\prime}$ exonuclease activity of NSP14. Although NSP15 has a uridine-specific endoribonuclease activity, its activity may be more important for host immune evasion than for genomic replication (Pillon et al., 2021). Assembled virus particles bud out of endoplasmic reticulum-to-Golgi intermediate compartments and have been suggested to exit the host cell via the lysosomal traffick- ing pathway (Ghosh et al., 2020).

Nucleoside analogs that inhibit the RdRp or terminate the nascent viral RNA chains are among the primary candidates for SARS-CoV-2 inhibition. Considering the effectivity of inhibiting proteases in controlling human immunodeficiency virus and hepatitis $\mathrm{C}$ virus infections, proteases involved in the replication cycle of SARS-CoV-2 are also deemed important targets for controlling SARS-CoV-2 infection. These proteases include not only virus-encoded proteases $\left(\mathrm{PL}^{\mathrm{pro}}\right.$ and $\mathrm{M}^{\mathrm{pro}}$ ) but also host proteases, such as TMPRSS2 and cathepsins $\mathrm{L}$ and $\mathrm{B}$. Other targets for SARS-CoV-2 inhibition include the $S$ protein and its interaction with $\mathrm{ACE} 2$; the endocytic pathway; lipid regulatory pathways; and the lysosomal trafficking pathway. Modulators of the immune response are also considered candidates for COVID-19 treatment, given the relative success of steroids in the treatment of the inflammatory stage of COVID-19 (The RECOVERY Collaborative Group, 2021). With these considerations, several groups have identified phytochemicals that inhibited SARS-CoV-2 production in vitro and have elucidated their targets in the SARS$\mathrm{CoV}-2$ replication cycle. Other groups have taken the reverse 
route and have identified inhibitors of specific proteins involved in the SARS-CoV-2 replication cycle and determined whether these activities would translate to inhibiting virus production in cell culture models. Together, these efforts have led to the identification of vascular plant secondary metabolites that have the potential to treat COVID-19.

\section{Alkaloids}

Alkaloids are naturally occurring organic compounds that carry at least one nitrogen atom typically within a heterocyclic ring. The nitrogen atoms in alkaloids are in the negative oxidation state, lending alkaloids their basic properties (Kurek, 2019). Alkaloids are structurally diverse and comprise one of the largest groups of plant secondary metabolites. A number of alkaloids from plants (Table 1) have been observed to inhibit SARS-CoV-2 components or infection in vitro. In two separate studies using Vero E6 cells, berbamine inhibited SARS-CoV-2 S pseudovirus entry, reduced genome replication, and reduced infectious virus production (Huang et al., 2021; Xia et al., 2021). In one of these studies, berbamine was found to inhibit the ion channel activity of the SARS-CoV$2 \mathrm{E}$ protein at a high concentration. In the same study, a berbamine derivative (BE-33) showed even more potent activity against SARS-CoV-2 infection $\left(\mathrm{EC}_{50}\right.$ of $0.94 \mu \mathrm{M}$ for viral titers) and higher binding affinity to the E protein ion channel than did berbamine (Xia et al., 2021). This derivative also reduced viral loads in the lungs and reduced inflammatory cytokines in human ACE2 (hACE2)-transgenic mice, suggesting anti-inflammatory properties that may be beneficial to severe COVID-19 cases. Berberine, another alkaloid, was observed to reduce infectious virus production but not viral RNA levels in Vero E6 cells, indicating that berberine affects stages later than genome replication (Pizzorno et al., 2020; Varghese et al., 2021). An immunofluorescence-based screening for FDA-approved drugs that inhibit viral genome replication, as indicated by dsRNA production, revealed bromhexine and reserpine, and two antiarrhythmic drugs with antimalarial activity, hydroquinidine and quinidine, as potential anti-SARS-CoV-2 agents (Ku et al., 2020). Other antimalarial alkaloids (quinacrine and quinine) have also been reported to inhibit SARS-CoV-2 infection in vitro (Große et al., 2021; Salas Rojas et al., 2021).

The iminosugar castanospemine and its prodrug, celgosivir, protected Vero E6 cells from SARS-CoV-2-induced cytopathic effects (CPE) and reduced viral genome replication (Clarke et al., 2021). Celgosivir treatment led to lower S protein levels, probably owing to its ability to inhibit $\alpha$-glucosidases, leading to improper S protein folding. A screening on natural products revealed the ability of cepharanthine, hernandezine, and neferine to inhibit SARS-CoV-2 S pseudovirus entry in ACE2expressing HEK293T (HEK293/ACE2) cells (He et al., 2021). Other studies have also shown that cepharanthine can protect Vero E6 and Calu-3 cells from authentic SARS-CoV-2 infection; one of these studies has proposed that cepharanthine disrupts the S-ACE2 interaction (Jan et al., 2021; Ohashi et al., 2021). The anti-SARS-CoV-2 potential of neferine and its analogs (isoliesinine and liesinine) have also been corroborated in a different study, where neferine inhibited $\mathrm{Ca}^{2+}$-de- pendent fusion of the viral envelope with the host membrane (Yang et al., 2021b).

Emetine, which has displayed inhibitory effects on Zika virus and Ebola virus (Yang et al., 2018), has been reported to reduce SARS-CoV-2 replication in a number of in vitro studies (Choy et al., 2020; Wang et al., 2020b; Jan et al., 2021; Kumar et al., 2021). A small observational study has also shown that, while emetine did not accelerate viral clearance, emetine appeared to improve blood oxygen concentrations and breathing difficulties among symptomatic COVID-19 patients (Fan et al., 2021). Meanwhile, homoharringtonine has been shown to protect Vero E6 cells from SARS-CoV-2 CPE and to reduce viral titers and RNA replication (Choy et al., 2020). Lycorine and oxysophoridine have also been shown to inhibit SARS-CoV-2 replication in Vero E6 cells (Zhang et al., 2020). Tetrandrine was demonstrated to inhibit the entry of SARS-CoV-2-S pseudoviruses in HEK293/ACE2 cells in a dose-dependent manner, likely owing to its ability to inhibit the two-pore calcium channel 2 (TPC2), which may be involved in the endocytic pathway of SARS-CoV-2 entry $(\mathrm{Ou}$ et al., 2020).

Derivatives of alkaloids have also exhibited anti-SARSCoV-2 effects in a number of studies, indicating that alkaloid structures can be optimized for the development of antiSARS-CoV-2 agents. Isatin derivatives were observed to inhibit SARS-CoV-2 M $\mathrm{M}^{\text {pro }}$ activity (Liu et al., 2020). Treatment with topotecan, an analog of the plant-derived alkaloid camptothecin, reduced morbidity and mortality rates in mice infected with SARS-CoV-2, with indications of reduced inflammatory responses (Ho et al., 2021). Derivatives of tylophorine, a naturally occurring alkaloids, have also demonstrated the ability to inhibit SARS-CoV-2 infection in vitro (Yang et al., 2020).

\section{Flavonoids}

Flavonoids comprise another large and structurally diverse group of secondary metabolites produced by plants. The basic flavonoid skeleton is characterized by 15 carbon atoms, wherein two primary aromatic rings (A and $\mathrm{B})$ are connected by three carbon atoms $\left(\mathrm{C}_{6}-\mathrm{C}_{3}-\mathrm{C}_{6}\right)$, which may be linked to a third ring (C) (Santos et al., 2017). Flavonoids often occur as aglycones (non-sugar forms), as well as glycosylated and methylated derivatives. Several flavonoids have displayed activity against SARS-CoV-2 infection (Table 2). Both baicalin and its aglycone baicalein have been observed to inhibit SARSCoV-2 infection in vitro in several studies, some of which have shown that these flavonoids inhibit $\mathrm{M}^{\text {pro }}$ activity (Huang et al., 2020; Jo et al., 2020; Su et al., 2020; Liu et al., 2021). Furthermore, baicalein reduced lung damage and lung inflammation in hACE2 transgenic mice infected with SARS-CoV-2, and baicalein treatment protected the mice from infectioninduced body weight loss (Song et al., 2021). Remarkably, a study has also shown that baicalin may inhibit the endoribonuclease activity of SARS-CoV-2 NSP15, which suggests an additional or alternative mode of action (Hong et al., 2021). Naturally occurring baicalein analogs (dihydromyricetin, myricetin, scutellarein, and quercetagetin) have also been demonstrated to inhibit $\mathrm{M}^{\text {pro }}$ (Liu et al., 2021). 
962 Españo et al.

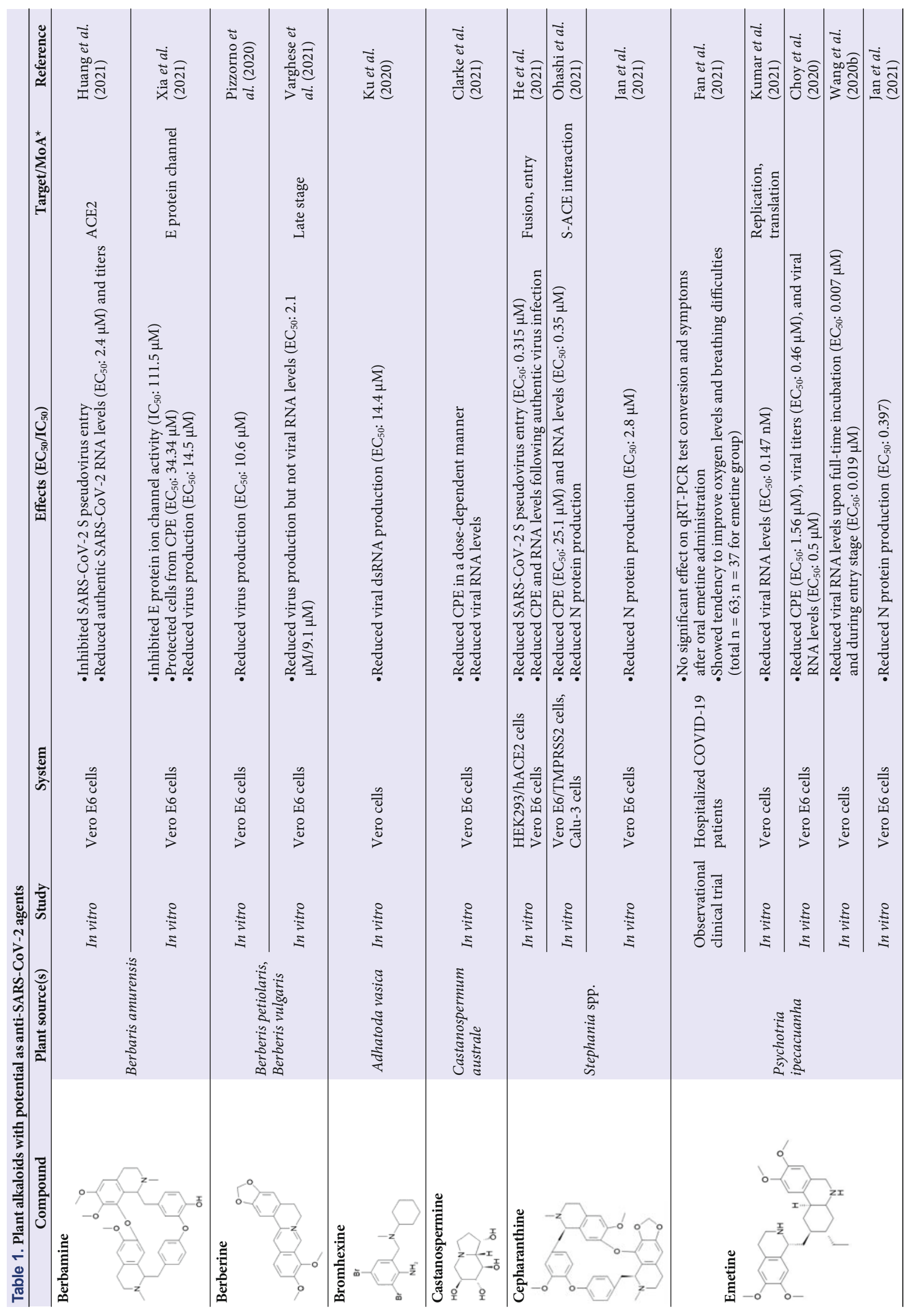


Phytochemicals against COVID-19 963

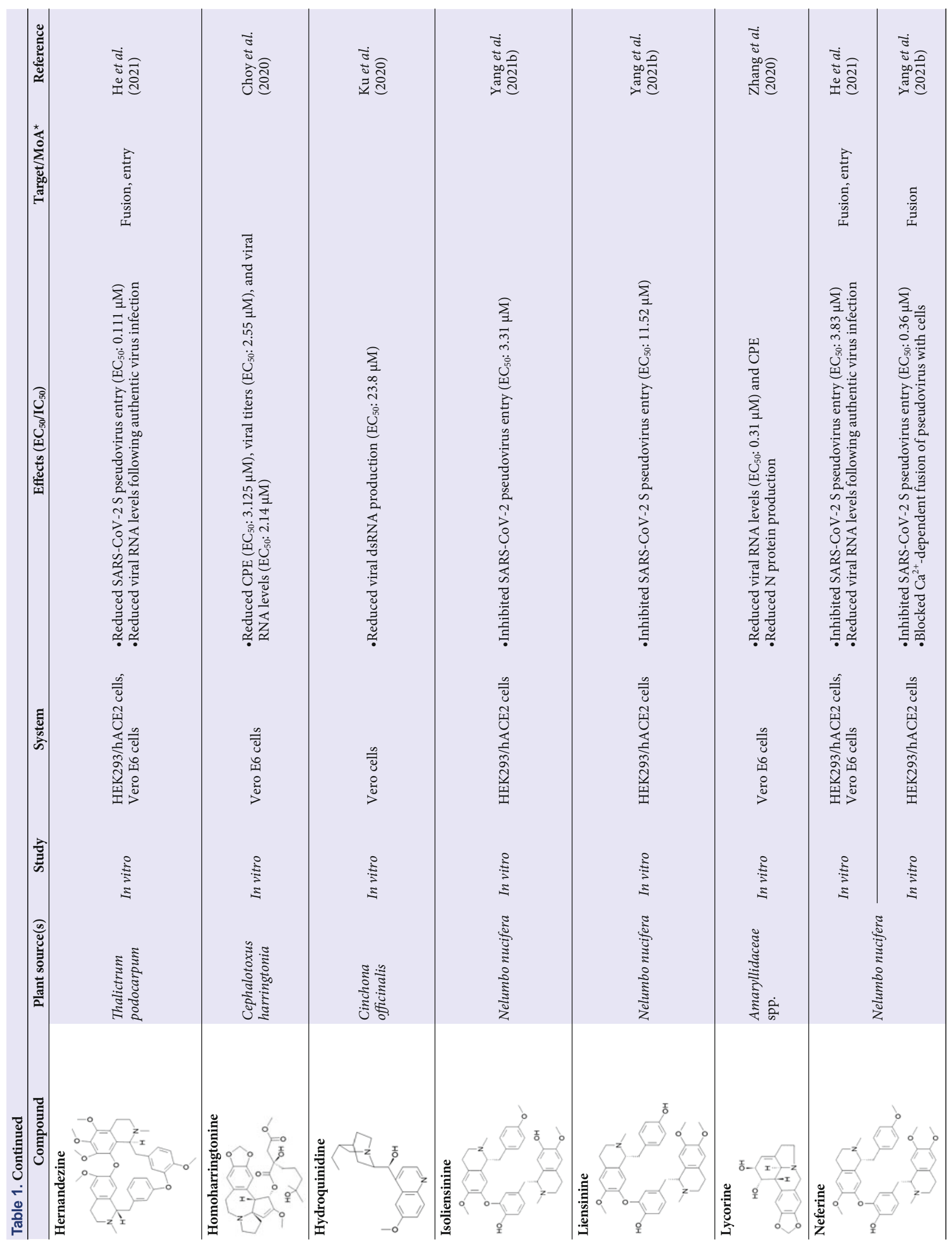


964 Españo et al.

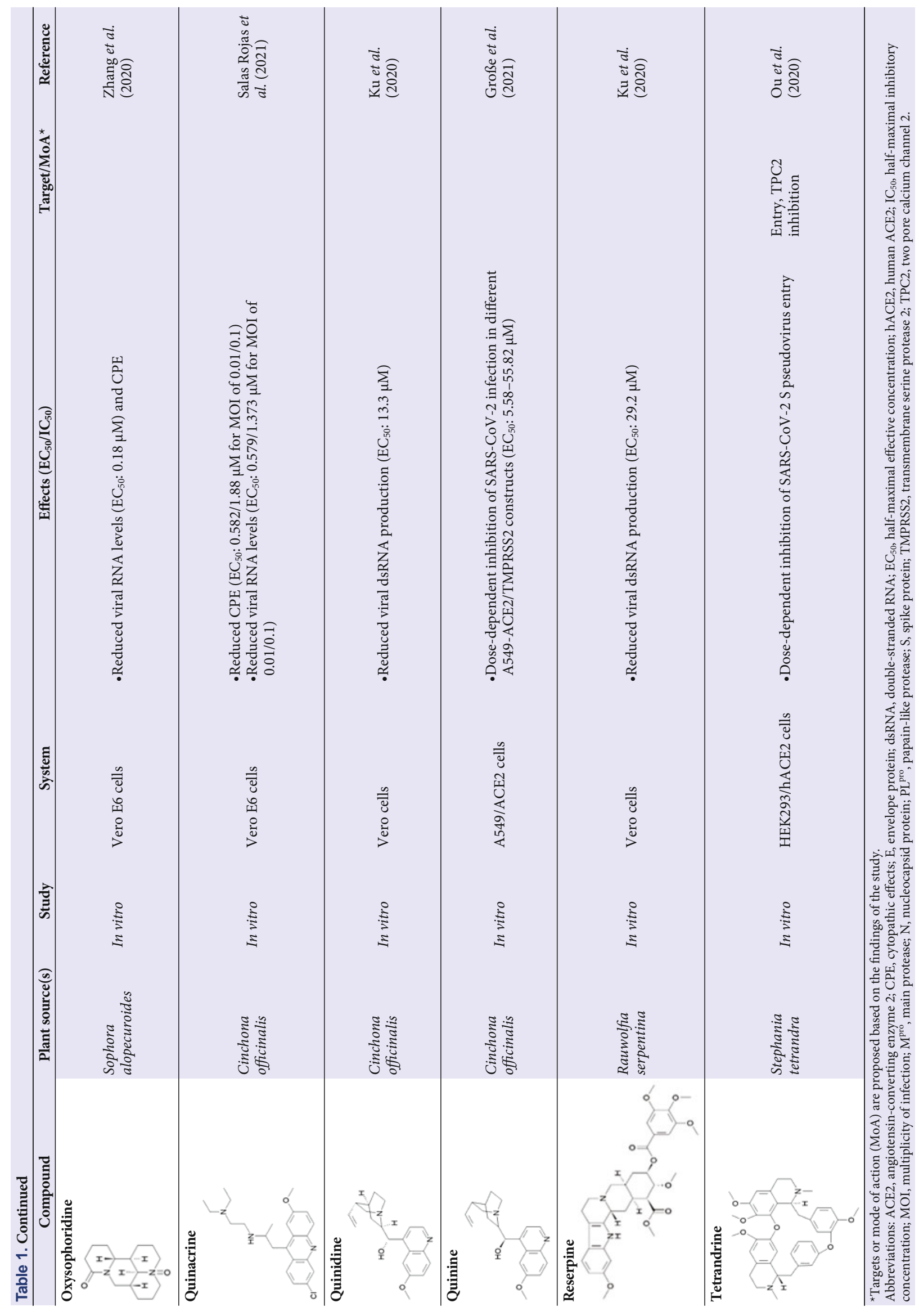




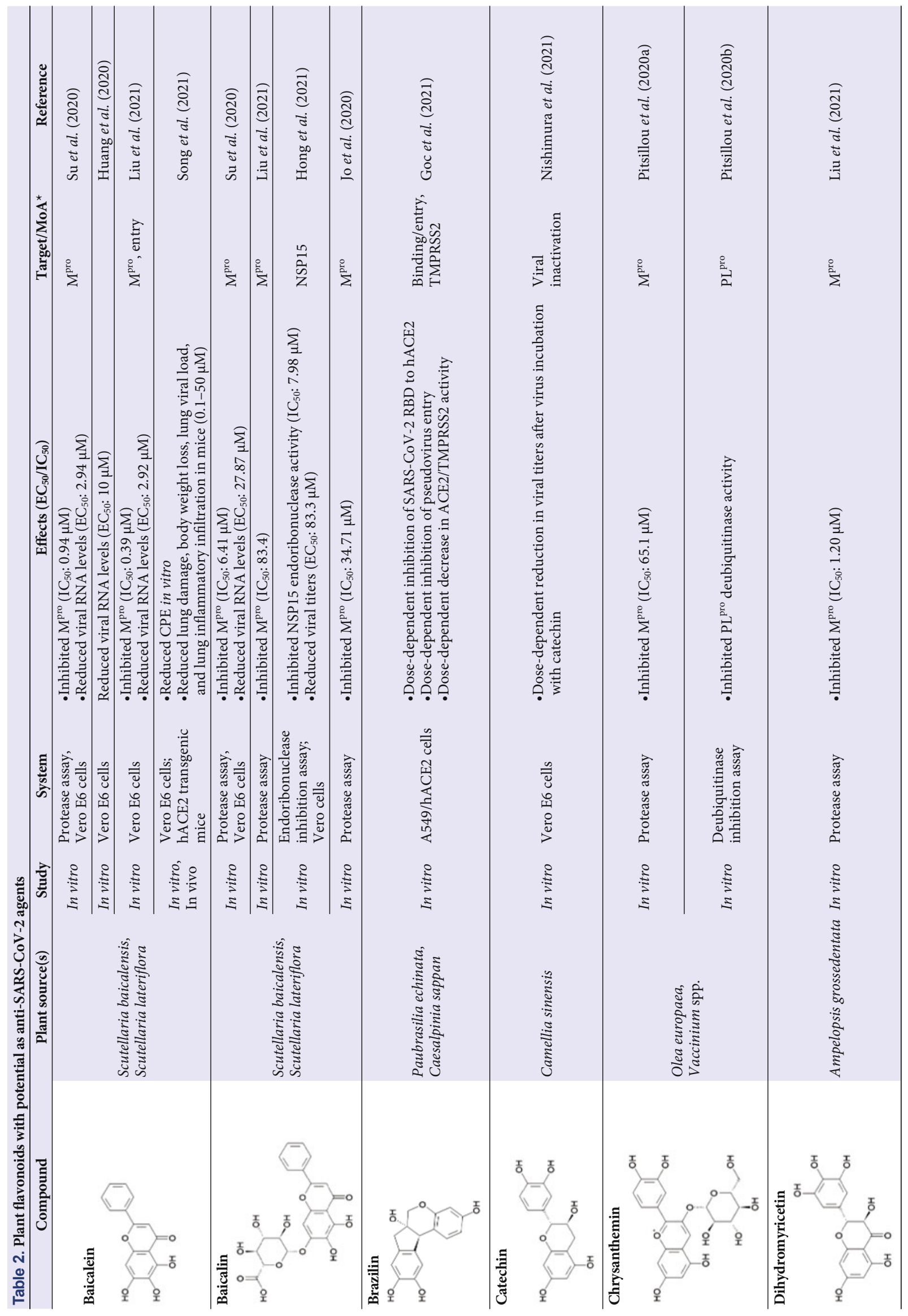




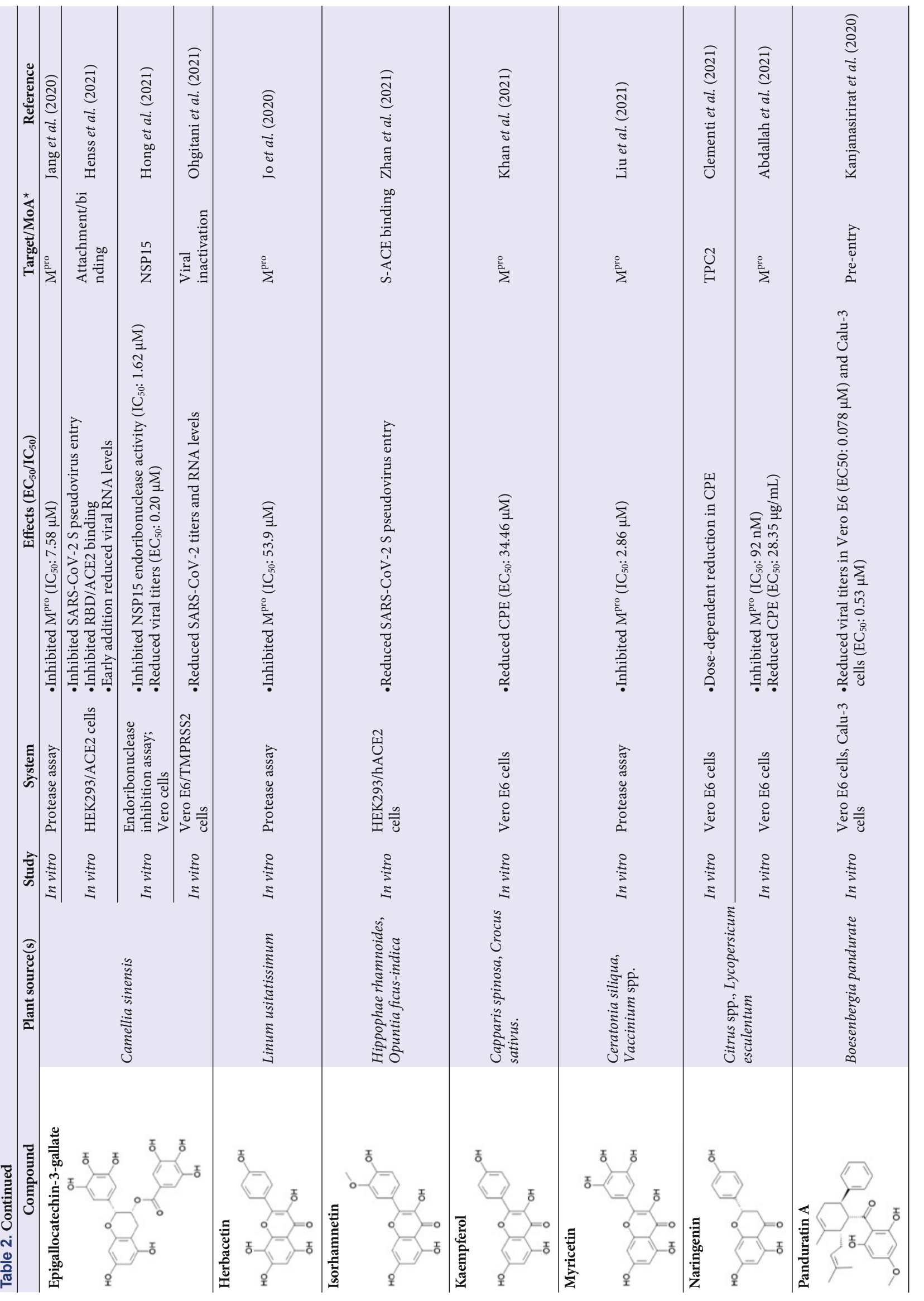


Phytochemicals against COVID-19 967

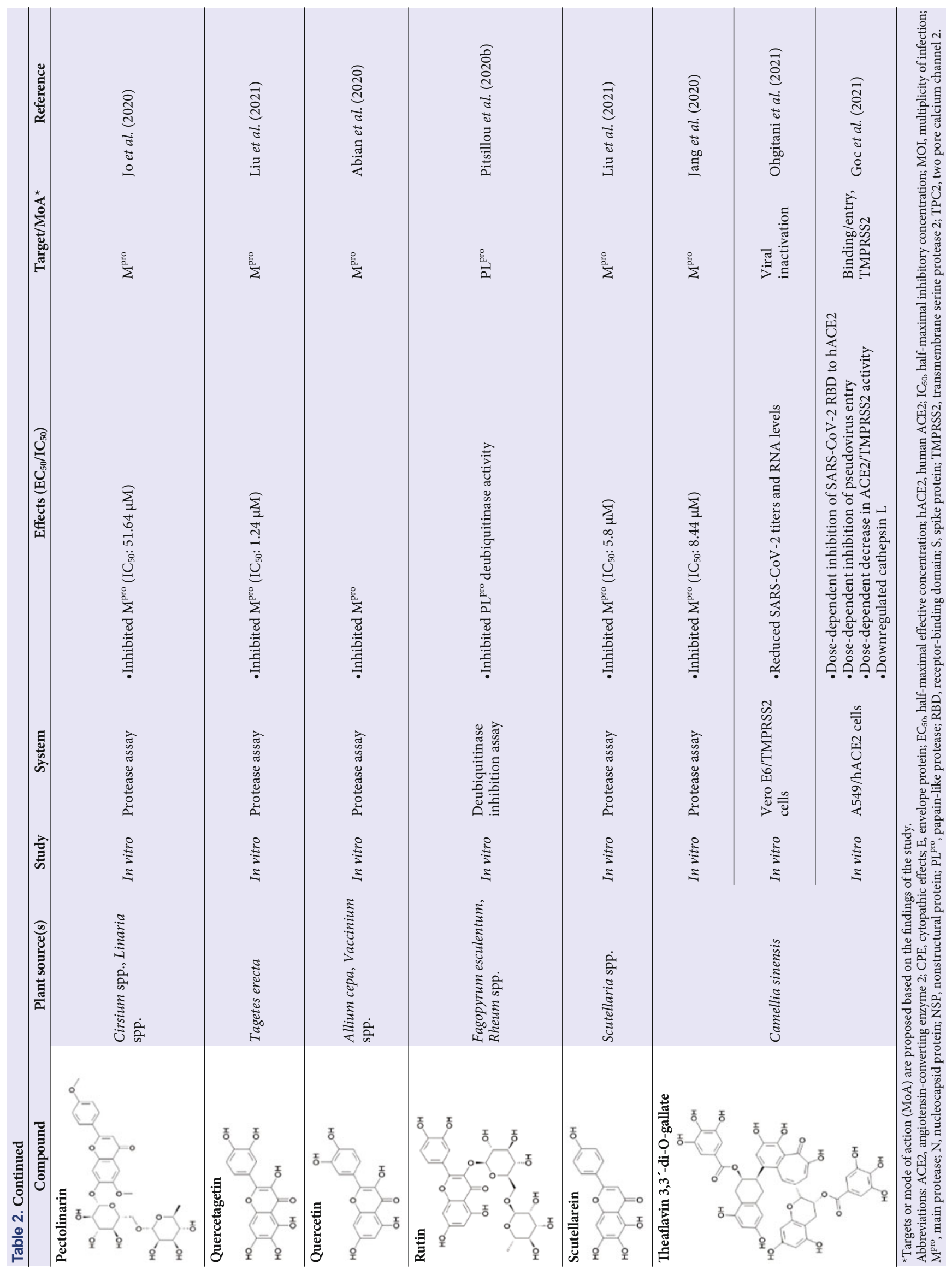


968 Españo et al.

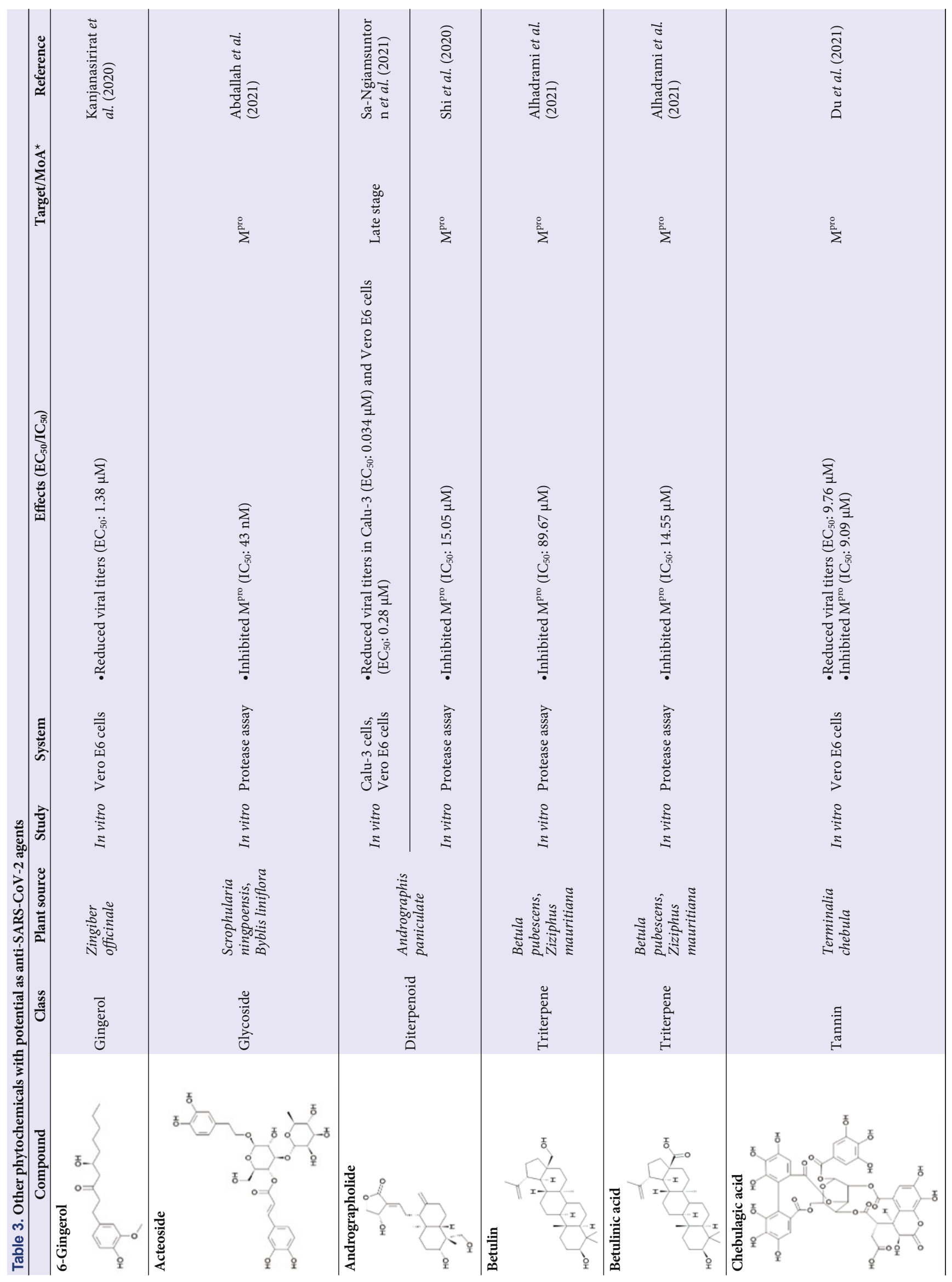


Phytochemicals against COVID-19 969

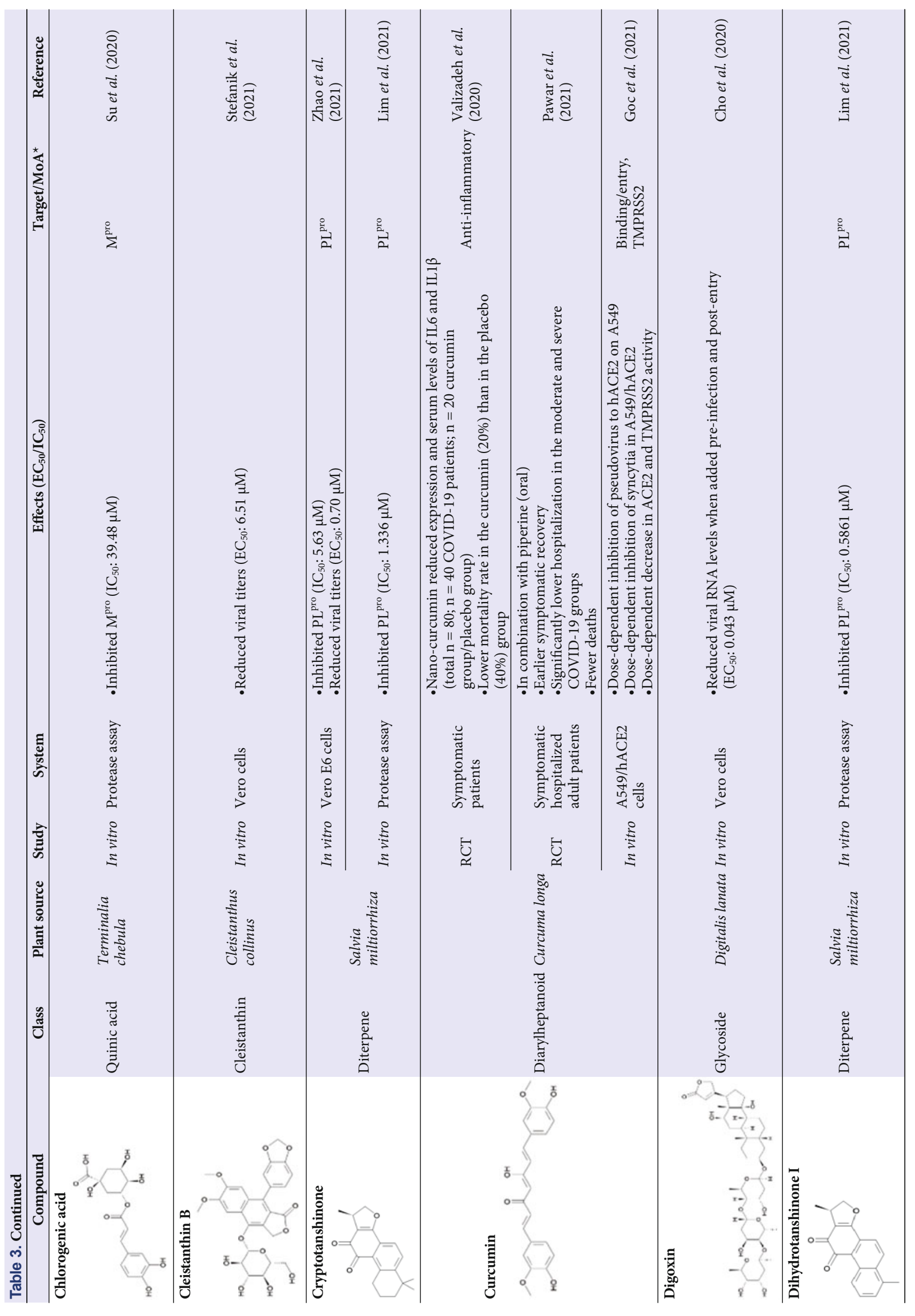


970 Españo et al.

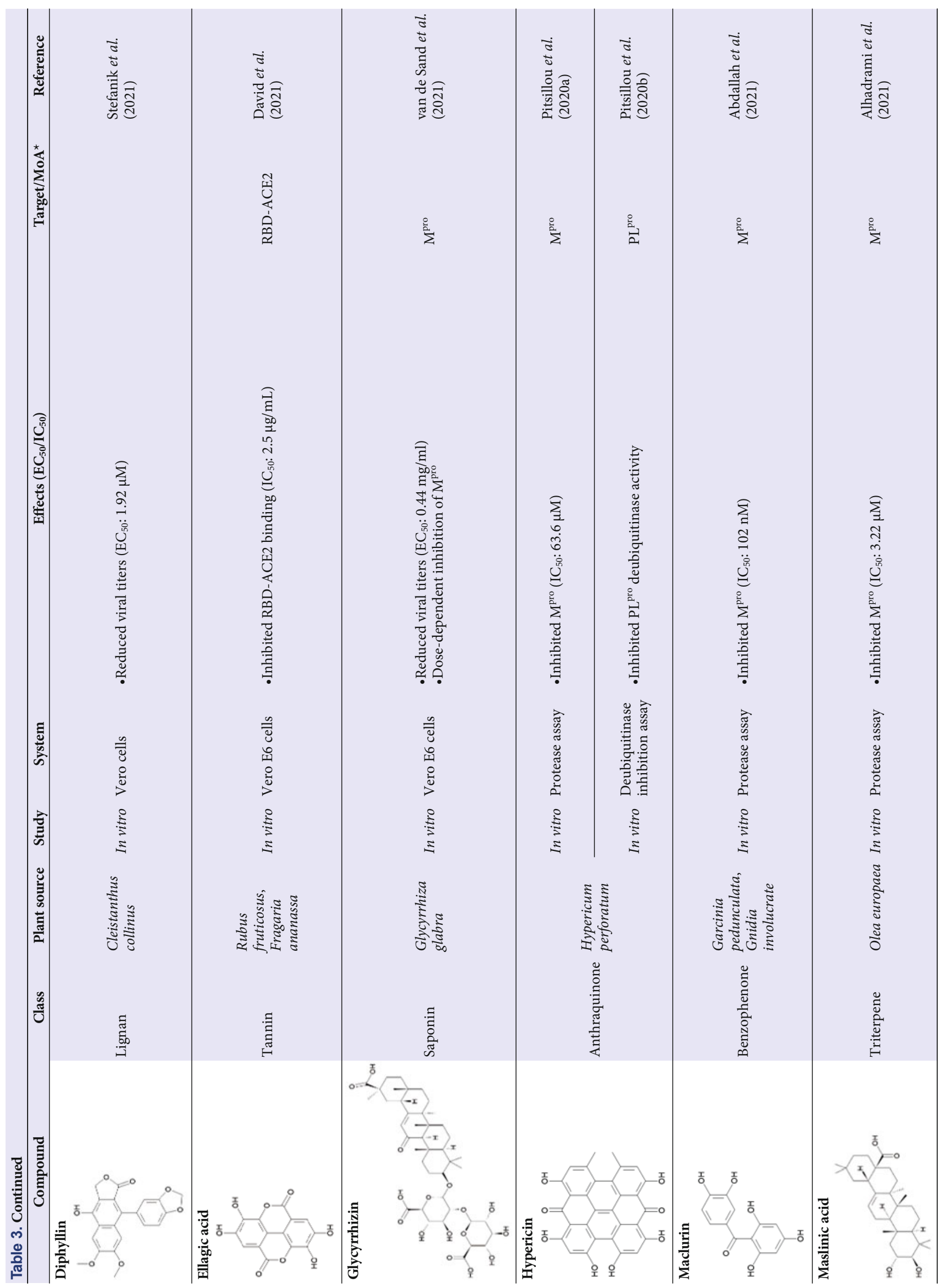


Phytochemicals against COVID-19 971

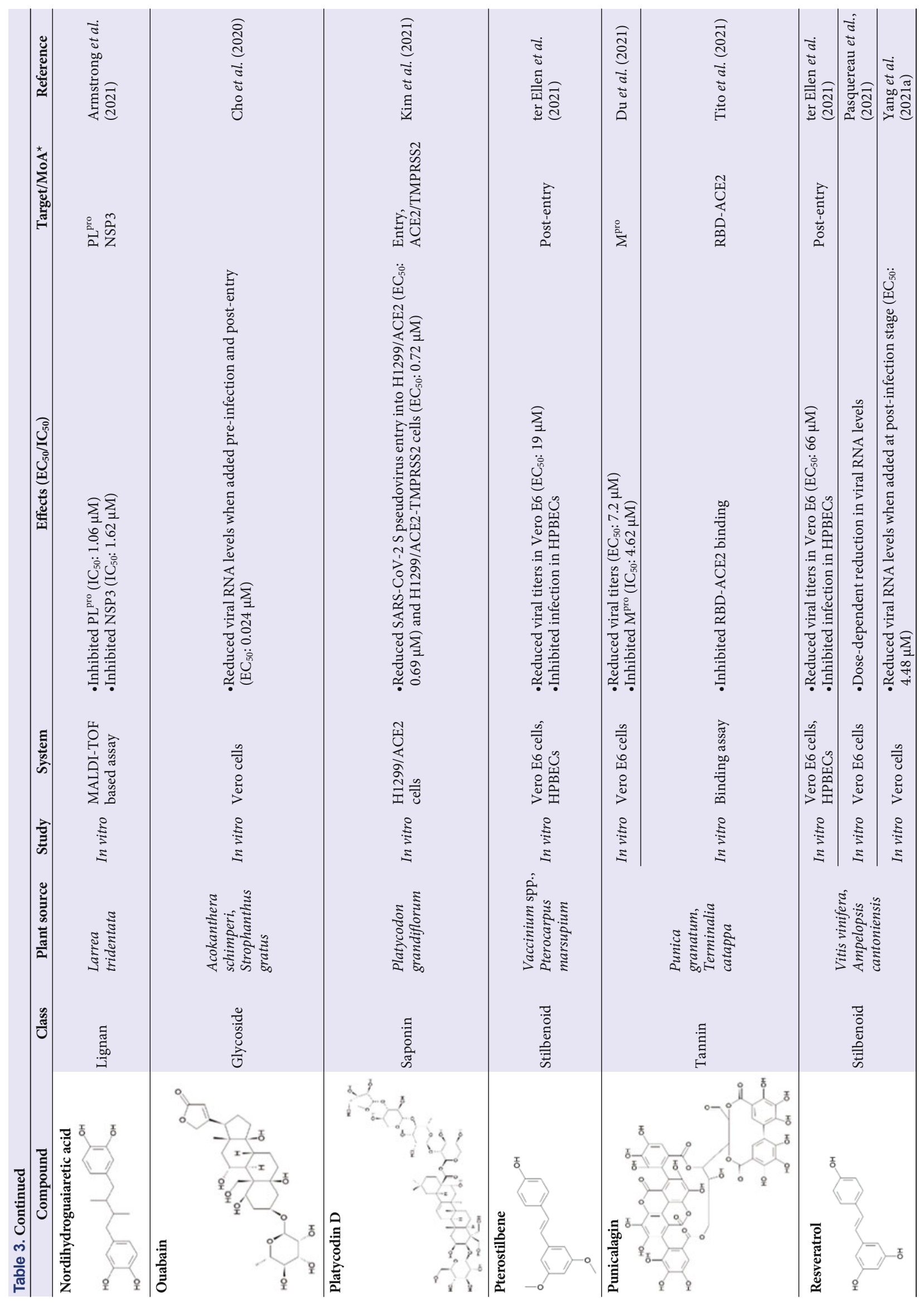


972 Españo et al.

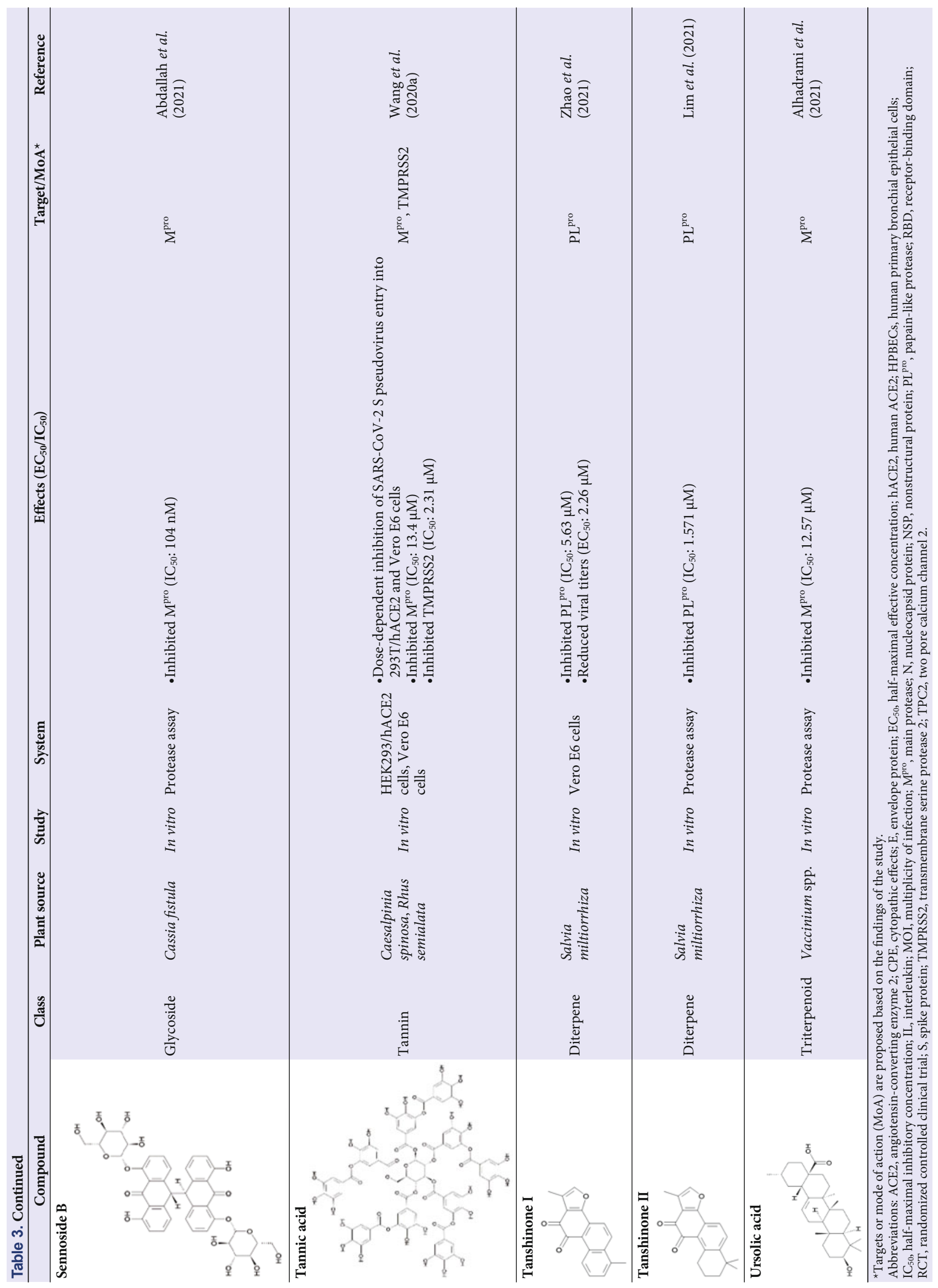


Brazilin has been shown to inhibit SARS-CoV-2 S pseudovirus entry into A549/ACE2 cells, likely owing to its ability to inhibit the RBD-ACE2 interaction or to inhibit ACE2 or TMPRSS2 activity (Goc et al., 2021). Isorhamnetin also inhibited SARS-CoV-2 S pseudovirus entry in HEK293/ACE2 cells, suggesting an ability to disrupt the S-ACE2 interaction (Zhan et al., 2021). Meanwhile, the addition of panduratin A to SARS-CoV-2-infected Vero E6 in Calu-3 cells reduced viral production in these cell culture models (Kanjanasirirat et al., 2020). Notably, pre-incubation of panduratin A with SARSCoV-2 particles reduced the infectivity of the virus in Vero E6 cells, suggesting that it affects pre-entry stages of infection.

Chrysanthemin, the 3-glucoside of cyanidin, has been reported to inhibit $\mathrm{M}^{\mathrm{pro}}$ and $\mathrm{PL}^{\mathrm{pro}}$ in separate studies (Pitsillou et al., 2020a, 2020b). Other flavonoids (herbacetin, kaempferol, pectolinarin, and quercetin) with the capacity to inhibit SARS-CoV-2 $\mathrm{M}^{\text {pro }}$ have also been reported in different studies (Abian et al., 2020; Jo et al., 2020; Khan et al., 2021). Meanwhile, rutin, a rutinose-bound form of quercetin, has been found to inhibit the deubiquitinase activity of $\mathrm{PL}^{\text {pro }}$ (Pitsillou et al., 2020b). Naringenin was observed to protect Vero E6 cells from SARS-CoV-2-induced CPE and has been suggested to inhibit $\mathrm{M}^{\text {pro }}$ and TPC2 (Abdallah et al., 2021; Clementi et al., 2021).

Flavonoids from the leaves of Camellia sinensis have shown inhibitory activity against a variety of viruses and have likewise shown inhibitory effects on SARS-CoV-2 infection in vitro (Xu et al., 2017). Epicatechin-3-gallate (EGCG) and theaflavin-3-3' -di-O-gallate (TF3) have displayed virucidal effects on SARS-CoV-2 particles (Nishimura et al., 2021; Ohgitani et al., 2021). Both have also been shown to inhibit SARSCoV-2 binding, entry, and $\mathrm{M}^{\text {pro }}$ activity (Jang et al., 2020; Goc et al., 2021; Henss et al., 2021). EGCG also inhibited the endoribonuclease activity of NSP15 (Hong et al., 2021), whereas TF3 appeared to downregulate cathepsin L levels, which may contribute to its inhibitory effects on SARS-CoV-2 entry (Goc et al., 2021). Whether EGCG or T3G inhibits all or some of these targets remains to determined. However, the findings listed here emphasize the breadth of pharmacological activities of some of these phytochemicals.

\section{Other Groups of Phytochemicals}

\section{Terpenes and terpenoids}

Several other groups of phytochemicals have also displayed anti-SARS-CoV-2 activity in vitro (Table 3 ). Among these are terpenes and terpenoids, which form one of the largest families of plant secondary metabolites. All terpenes are composed of isoprene units $\left(\mathrm{C}_{5} \mathrm{H}_{8}\right)$ and are further classified depending on the number of isoprene units (e.g., diterpenes have four isoprene units, while triterpenes have six) (Perveen, 2021). Terpenes that have additional functional groups or oxidized methyl groups are called terpenoids. The diterpenoid andrographolide and its fluorescent derivative have been reported to inhibit $\mathrm{M}^{\text {pro }}$ (Shi et al., 2020). Andrographolide also reduced SARS-CoV-2 production in Vero E6 and Calu-3 cells and has been proposed to inhibit late stages of infection (Sa-Ngiamsuntorn et al., 2021). Diterpenes cryptotanshinone, tanshinone I, tanshinone II, and dihydrotanshinone
I have all demonstrated the capacity to inhibit $\mathrm{PL}^{\text {pro }}$ in separate studies (Lim et al., 2021; Zhao et al., 2021). Furthermore, cryptotanshinone and tanshinone I reduced SARS-CoV-2 production in Vero E6 cells (Zhao et al., 2021). Triterpenoids from olive leaves (betulin, betulinic acid, maslinic acid, and ursolic acid) were found to inhibit $\mathrm{M}^{\text {pro }}$ through an enzyme assay (Alhadrami et al., 2021). Triterpene glycosides, also known as saponins, such as glycyrrhizin and platycodin D, have also been observed to have anti-SARS-CoV-2 activity. In particular, glycyrrhizin inhibited the production of infectious virus particles in Vero E6 cells and inhibited $\mathrm{M}^{\text {pro }}$ in a dose-dependent manner (van de Sand et al., 2021). Meanwhile, platycodin D reduced SARS-CoV-2 S pseudovirus entry into H12299/ACE2 and H12299/ACE2-TMPRSS2 cells (Kim et al., 2021).

\section{Curcumin}

Curcumin, which has demonstrated a broad spectrum of pharmacological activities, including anti-inflammatory and antiviral effects (Amalraj et al., 2017), has also been reported to inhibit SARS-CoV-2 S pseudovirus entry into A549/hACE2 cells (Goc et al., 2021). Curcumin is insoluble in water, and, consequently, has poor bioavailability (Anand et al., 2007); several formulations of curcumin have been designed to improve its bioavailability for clinical application. Two small randomized controlled clinical trials have reported the potential benefits of different curcumin formulations to COVID19 patients (Table 3). In one of these studies, an oral nanomicellular formulation of curcumin was given for 14 days to newly diagnosed COVID-19 patients who also received standard of care (interferon beta-1b, bromhexine, and atorvastatin) (Valizadeh et al., 2020). Curcumin treatment among COVID19 patients resulted in decreased interleukin (IL)- $1 \beta$ and IL-6 mRNA and serum levels relative to baseline, whereas the mRNA and serum levels of these pro-inflammatory cytokines did not significantly decrease in the placebo group. Mortality due to COVID-19 was also lower in the curcumin treatment group (20\%) than in the placebo group (40\%). In another study, an oral formulation containing curcumin and piperine (added to improve curcumin bioavailability) was observed to accelerate symptom recovery, shorten hospital stay, and reduce mortality rates among hospitalized COVID-19 patients who received COVID-19 standard of care, indicating that the formulation is a suitable adjuvant therapy for symptomatic patients (Pawar et al., 2021).

\section{Other phytochemicals}

Cardiac glycosides digoxin and ouabain (Table 3) have been reported to inhibit viral genome replication in Vero E6 cells (Cho et al., 2020). Sennoside B and acteoside, both glycosides, have been reported to inhibit $\mathrm{M}^{\text {pro }}$ (Abdallah et al., 2021). Phytochemicals belonging to other groups, such as maclurin (benzophenone) and chlorogenic acid (quinic acid) have also been reported to inhibit $\mathrm{M}^{\text {pro }}$ activity (Su et al., 2020; Abdallah et al., 2021). Tannins, which are high molecular-weight polyphenols from plants, such as chebulagic acid, punicalagin, and tannic acid, have all displayed the ability to inhibit $\mathrm{M}^{\text {pro }}$ activity (Wang et al., 2020a; Du et al., 2021; Tito et al., 2021). Punicalagin and ellagic acid were also observed to interfere 
with the S protein or RBD interaction with ACE2 (David et al., 2021; Tito et al., 2021).

The lignan diphyllin reduced SARS-CoV-2 titers in Vero cells (Stefanik et al., 2021). Nordihydroguaiaretic acid, another lignan, has been reported to inhibit NSP3 and one of its domains, $\mathrm{PL}^{\mathrm{pro}}$, in a matrix-assisted laser desorption ionization time-of-flight-based deubiquitylase assay (Armstrong et al., 2021). The stilbenoid resveratrol has been observed to inhibit viral genome replication and virus production in Vero and Vero E6 cells, and has been found to inhibit SARS-CoV2 infection in human primary bronchial epithelial cells (Pasquereau et al., 2021; ter Ellen et al., 2021; Yang et al., 2021a). Pterostilbene, another stilbenoid, has likewise been reported to reduce virus production in Vero E6 cells and to inhibit SARS-CoV-2 infection in human primary bronchial epithelial cells (ter Ellen et al., 2021). Gingerol, a polyphenol from ginger, has been reported to reduce viral titers in Vero E6 cells. Meanwhile, hypericin, an anthraquinone, has been revealed to inhibit $\mathrm{M}^{\mathrm{pro}}$ and $\mathrm{PL}^{\mathrm{pro}}$ in separate screening assays (Pitsillou et al., 2020a, 2020b).

\section{Perspectives and Conclusion}

The diversity of plant secondary metabolites lend them a huge breadth of pharmacological activities and have made them a rich source of drugs for several disease states. However, the structural complexity of phytochemicals makes them difficult to produce and synthesize in the industrial scale, which is part of the reason why most pharmaceutical companies favor synthetic small molecules for antiviral screening and development. Phytochemicals may also possess suboptimal activity (i.e., require high concentrations that are not achievable in human plasma) and may have poor bioavailability. However, steady progress in synthetic chemistry and in biotechnology have recently allowed the synthesis or semisynthesis of large, complex natural products (Beutler, 2009; Atanasov et al., 2021). Furthermore, even for synthetic molecules, the identification of pharmacophores is imperative to allow derivatization of compounds for improved efficacy and bioavailability and even for structural simplicity, so the requirement for optimization is not unique to phytochemicals. Advancements in the field of drug delivery, as exemplified by the orally administered nano-curcumin that we have cited here, have also improved the systemic bioavailability and pharmacological profiles of phytochemicals in pre-clinical models (Rahman et al., 2020). The technologies for compound optimization and biosynthesis continue to improve and may eventually address some of the limitations to the clinical application of plant-derived antiviral compounds. Thus, we must continue to build our repository of plant-based antivirals, so that the semi-synthetic/biosynthetic techniques could be applied to these plant products as soon as the technology becomes available. Furthermore, studies identifying phytochemicals with broad-spectrum antiviral potential should be performed as they may allow us to focus our efforts on optimizing semi- and biosynthetic techniques to pathways relevant to these compounds.

As we have presented, plants provide a vast array of candidates for the treatment of COVID-19. Although we have not named them here, several of these phytochemicals have exhibited activity against other coronaviruses (Islam et al., 2020), indicating that they may be used against future coronavirus outbreaks. Some of these compounds (e.g., catechin and emetine) have also demonstrated the ability to inhibit infection with viruses belonging to other families, which suggests their potential as broad-spectrum antivirals (Ali et al., 2021). Based on the relative successes of plant secondary metabolites in other disease states, such as cancer and antiparasitic infections, the development of plant bioactive compounds from bench-to-bedside is not impossible. Likely, the lack of plant antivirals stems from the parallel lack of impetus to develop treatment agents for acute viral diseases, which is one of the reasons for the slow global response to the COVID-19 pandemic. Concerted efforts are needed to maximize resources, including phytochemicals, for the development of treatment agents for COVID-19 and other viral diseases to ease the blow of large viral outbreaks in the future.

\section{Acknowledgements}

This work was supported by Korea University Grant (K2112821). Figure 1 was adapted from the "Life Cycle of Coronavirus" from BioRender.com.

\section{Conflict of Interest}

The authors have no conflict of interest to disclose.

\section{References}

Abdallah, H.M., El-Halawany, A.M., Sirwi, A., El-Araby, A.M., Mohamed, G.A., Ibrahim, S.R.M., Koshak, A.E., Asfour, H.Z., Awan, Z.A., and Elfaky, M.A. 2021. Repurposing of some natural product isolates as SARS-COV-2 main protease inhibitors via in vitro cell free and cell-based antiviral assessments and molecular modeling approaches. Pharmaceuticals 14, 213.

Abian, O., Ortega-Alarcon, D., Jimenez-Alesanco, A., Ceballos-Laita, L., Vega, S., Reyburn, H.T., Rizzuti, B., and Velazquez-Campoy, A. 2020. Structural stability of SARS-CoV-2 3CLpro and identification of quercetin as an inhibitor by experimental screening. Int. J. Biol. Macromol. 164, 1693-1703.

Alhadrami, H.A., Sayed, A.M., Sharif, A.M., Azhar, E.I., and Rateb, M.E. 2021. Olive-derived triterpenes suppress SARS COV-2 main protease: a promising scaffold for future therapeutics. Molecules 26, 2654.

Ali, S.I., Sheikh, W.M., Rather, M.A., Venkatesalu, V., Muzamil Bashir, S., and Nabi, S.U. 2021. Medicinal plants: treasure for antiviral drug discovery. Phytother. Res. 35, 3447-3483.

Amalraj, A., Pius, A., Gopi, S., and Gopi, S. 2017. Biological activities of curcuminoids, other biomolecules from turmeric and their derivatives - a review. J. Tradit. Complement. Med. 7, 205-233.

Anand, P., Kunnumakkara, A.B., Newman, R.A., and Aggarwal, B.B. 2007. Bioavailability of curcumin: problems and promises. Mol. Pharm. 4, 807-818.

Armstrong, L.A., Lange, S.M., Dee Cesare, V., Matthews, S.P., Nirujogi, R.S., Cole, I., Hope, A., Cunningham, F., Toth, R., Mukherjee, R., et al. 2021. Biochemical characterization of protease activity of Nsp3 from SARS-CoV-2 and its inhibition by nanobodies. PLoS ONE 16, e0253364. 
Atanasov, A.G., Zotchev, S.B., Dirsch, V.M., International Natural Product Sciences Taskforce, and Supuran, C.T. 2021. Natural products in drug discovery: advances and opportunities. Nat. Rev. Drug Discov. 20, 200-216.

Beutler, J.A. 2009. Natural products as a foundation for drug discovery. Curr. Protoc. Pharmacol. 46, 9.11.1-9.11.21.

Cho, J., Lee, Y.J., Kim, J.H., Kim, S.I., Kim, S.S., Choi, B.S., and Choi, J.H. 2020. Antiviral activity of digoxin and ouabain against SARSCoV-2 infection and its implication for COVID-19. Sci. Rep. 10, 16200 .

Choy, K.T., Wong, A.Y., Kaewpreedee, P., Sia, S.F., Chen, D., Hui, K.P.Y., Chu, D.K.W., Chan, M.C.W., Cheung, P.P., Huang, X., et al. 2020. Remdesivir, lopinavir, emetine, and homoharringtonine inhibit SARS-CoV-2 replication in vitro. Antiviral Res. 178, 104786.

Clarke, E.C., Nofchissey, R.A., Ye, C., and Bradfute, S.B. 2021. The iminosugars celgosivir, castanospermine and UV-4 inhibit SARSCoV-2 replication. Glycobiology 31, 378-384.

Clementi, N., Scagnolari, C., D'Amore, A., Palombi, F., Criscuolo, E., Frasca, F., Pierangeli, A., Mancini, N., Antonelli, G., Clementi, M., et al. 2021. Naringenin is a powerful inhibitor of SARS-CoV2 infection in vitro. Pharmacol. Res. 163, 105255.

David, A.B., Diamant, E., Dor, E., Barnea, A., Natan, N., Levin, L., Chapman, S., Mimran, L.C., Epstein, E., Zichel, R., et al. 2021. Identification of SARS-CoV-2 receptor binding inhibitors by in vitro screening of drug libraries. Molecules 26, 3213.

Du, R., Cooper, L., Chen, Z., Lee, H., Rong, L., and Cui, Q. 2021. Discovery of chebulagic acid and punicalagin as novel allosteric inhibitors of SARS-CoV-2 3CLpro. Antiviral Res. 190, 105075.

Fan, S., Zhen, Q., Chen, C., Wang, W., Wu, Q., Ma, H., Zhang, C., Zhang, L., Lu, B., Ge, H., et al. 2021. Clinical efficacy of low-dose emetine for patients with COVID-19: a real-world study. J. BioX Res. 4, 53-59.

Ghosh, S., Dellibovi-Ragheb, T.A., Kerviel, A., Pak, E., Qiu, Q., Fisher, M., Takvorian, P.M., Bleck, C., Hsu, V.W., Fehr, A.R., et al. 2020. $\beta$-Coronaviruses use lysosomes for egress instead of the biosynthetic secretory pathway. Cell 183, 1520-1535.

Goc, A., Sumera, W., Rath, M., and Niedzwiecki, A. 2021. Phenolic compounds disrupt spike-mediated receptor-binding and entry of SARS-CoV-2 pseudo-virions. PLoS ONE 16, e0253489.

Große, M., Ruetalo, N., Layer, M., Hu, D., Businger, R., Rheber, S., Setz, C., Rauch, P., Auth, J., Fröba, M., et al. 2021. Quinine inhibits infection of human cell lines with SARS-CoV-2. Viruses 13, 647.

He, C.L., Huang, L.Y., Wang, K., Gu, C.J., Hu, J., Zhang, G.J., Xu, W., Xie, Y.H., Tang, N., and Huang, A.L. 2021. Identification of bis-benzylisoquinoline alkaloids as SARS-CoV-2 entry inhibitors from a library of natural products. Sig. Transduct. Target. Ther. 6, 131 .

Henss, L., Auste, A., Schürmann, C., Schmidt, C., von Rhein, C., Mühlebach, M.D., and Schnierle, B.S. 2021. The green tea catechin epigallocatechin gallate inhibits SARS-CoV-2 infection. $J$. Gen. Virol. 102, 001574.

Ho, J.S.Y., Mok, B.W.Y., Campisi, L., Jordan, T., Yildiz, S., Parameswaran, S., Wayman, J.A., Gaudreault, N.N., Meekins, D.A., Indran, S.V., et al. 2021. TOP1 inhibition therapy protects against SARS-CoV-2-induced lethal inflammation. Cell 184, 2618-2632.

Hoffmann, M., Kleine-Weber, H., Schroeder, S., Krüger, N., Herrler, T., Erichsen, S., Schiergens, T.S., Herrler, G., Wu, N.H., Nitsche, A., et al. 2020. SARS-CoV-2 cell entry depends on ACE2 and TMPRSS 2 and is blocked by a clinically proven protease inhibitor. Cell 181, 271-280.

Hong, S., Seo, S.H., Woo, S.J., Kwon, Y., Song, M., and Ha, N.C. 2021. Epigallocatechin gallate inhibits the uridylate-specific endoribonuclease Nsp15 and efficiently neutralizes the SARS-CoV-2 strain. J. Agric. Food Chem. 69, 5948-5954.

Huang, S., Liu, Y., Zhang, Y., Zhang, R., Zhu, C., Fan, L., Pei, G., Zhang, B., and Shi, Y. 2020. Baicalein inhibits SARS-CoV-2/VSV replication with interfering mitochondrial oxidative phosphorylation in a MPTP dependent manner. Sig. Transduct. Target. Ther. $5,266$.

Huang, L., Yuen, T.T.T., Ye, Z., Liu, S., Zhang, G., Chu, H., and Yue, J. 2021. Berbamine inhibits SARS-CoV-2 infection by compromising TRPMLs-mediated endolysosomal trafficking of ACE2. Sig. Transduct. Target. Ther. 6, 168 .

Islam, M.T., Sarkar, C., El-Kersh, D.M., Jamaddar, S., Uddin, S.J., Shilpi, J.A., and Mubarak, M.S. 2020. Natural products and their derivatives against coronavirus: a review of the non-clinical and pre-clinical data. Phytother. Res. 34, 2471-2492.

Jan, J.T., Cheng, T.R., Juang, Y.P., Ma, H.H., Wu, Y.T., Yang, W.B., Cheng, C.W., Chen, X., Chou, T.H., Shie, J.J., et al. 2021. Identification of existing pharmaceuticals and herbal medicines as inhibitors of SARS-CoV-2 infection. Proc. Natl. Acad. Sci. USA 118, e2021579118.

Jang, M., Park, Y.I., Cha, Y.E., Park, R., Namkoong, S., Lee, J.I., and Park, J. 2020. Tea polyphenols EGCG and theaflavin inhibit the activity of SARS-CoV-2 3CL-protease in vitro. Evid. Based Complement. Alternat. Med. 2020, 5630838.

Jo, S., Kim, S., Kim, D.Y., Kim, M.S., and Shin, D.H. 2020. Flavonoids with inhibitory activity against SARS-CoV-2 3CLpro. J. Enzyme Inhib. Med. Chem. 35, 1539-1544.

Kanjanasirirat, P., Suksatu, A., Manopwisedjaroen, S., Munyoo, B., Tuchinda, P., Jearawuttanakul, K., Seemakhan, S., Charoensutthivarakul, S., Wongtrakoongate, P., Rangkasenee, N., et al. 2020. High-content screening of Thai medicinal plants reveals Boesenbergia rotunda extract and its component Panduratin A as antiSARS-CoV-2 agents. Sci. Rep. 10, 19963.

Khan, A., Heng, W., Wang, Y., Qiu, J., Wei, X., Peng, S., Saleem, S., Khan, M., Ali, S.S., and Wei, D.Q. 2021. In silico and in vitro evaluation of kaempferol as a potential inhibitor of the SARSCoV-2 main protease (3CLpro). Phytother. Res. 35, 2841-2845.

Kim, T.Y., Jeon, S., Jang, Y., Gotina, L., Won, J., Ju, Y.H., Kim, S., Jang, M.W., Won, W., Park, M.G., et al. 2021. Platycodin D, a natural component of Platycodon grandiflorum, prevents both lysosome- and TMPRSS2-driven SARS-CoV-2 infection by hindering membrane fusion. Exp. Mol. Med. 53, 956-972.

Ku, K.B., Shin, H.J., Kim, H.S., Kim, B.T., Kim, S.J., and Kim, C. 2020. Repurposing screens of FDA-approved drugs identify 29 inhibitors of SARS-CoV-2. J. Microbiol. Biotechnol. 30, 1843-1853.

Kumar, R., Afsar, M., Khandelwal, N., Chander, Y., Riyesh, T., Dedar, R.K., Gulati, B.R., Pal, Y., Barua, S., Tripathi, B.N., et al. 2021. Emetine suppresses SARS-CoV-2 replication by inhibiting interaction of viral mRNA with eIF4E. Antiviral Res. 189, 105056.

Kurek, J. 2019. Introductory Chapter: Alkaloids - Their Importance in Nature and for Human Life. IntechOpen, doi: 10.5772/ intechopen.85400. Available from: https://www.intechopen.com/ chapters/66742.

Lim, C.T., Tan, K.W., Wu, M., Ulferts, R., Armstrong, L.A., Ozono, E., Drury, L.S., Milligan, J.C., Zeisner, T.U., Zeng, J., et al. 2021. Identifying SARS-CoV-2 antiviral compounds by screening for small molecule inhibitors of Nsp3 papain-like protease. Biochem. J. 478, 2517-2531.

Liu, P., Liu, H., Sun, Q., Liang, H., Li, C., Deng, X., Liu, Y., and Lai, L. 2020. Potent inhibitors of SARS-CoV-2 3C-like protease derived from $\mathrm{N}$-substituted isatin compounds. Eur. J. Med. Chem. 206, 112702.

Liu, H., Ye, F., Sun, Q., Liang, H., Li, C., Li, S., Lu, R., Huang, B., Tan, W., and Lai, L. 2021. Scutellaria baicalensis extract and baicalein inhibit replication of SARS-CoV-2 and its 3C-like protease in vitro. J. Enzyme Inhib. Med. Chem. 36, 497-503.

Nishimura, H., Okamoto, M., Dapat, I., Katumi, M., and Oshitani, H. 2021. Inactivation of SARS-CoV-2 by catechins from green tea. Jpn. J. Infect. Dis. 74, 421-423.

Ohashi, H., Watashi, K., Saso, W., Shionoya, K., Iwanami, S., Hirokawa, T., Shirai, T., Kanaya, S., Ito, Y., Kim, K.S., et al. 2021. Po- 
tential anti-COVID-19 agents, cepharanthine and nelfinavir, and their usage for combination treatment. iScience 24, 102367.

Ohgitani, E., Shin-Ya, M., Ichitani, M., Kobayashi, M., Takihara, T., Kawamoto, M., Kinugasa, H., and Mazda, O. 2021. Significant inactivation of SARS-CoV-2 In vitro by a green tea catechin, a catechin-derivative, and black tea galloylated theaflavins. Molecules 26, 3572.

Ou, X., Liu, Y., Lei, X., Li, P., Mi, D., Ren, L., Guo, L., Guo, R., Chen, T., Hu, J., et al. 2020. Characterization of spike glycoprotein of SARS-CoV-2 on virus entry and its immune cross-reactivity with SARS-CoV. Nat. Commun. 11, 1620.

Pasquereau, S., Nehme, Z., Haidar Ahmad, S., Daouad, F., Van Assche, J., Wallet, C., Schwartz, C., Rohr, O., Morot-Bizot, S., and Herbein, G. 2021. Resveratrol inhibits HCoV-229E and SARSCoV-2 coronavirus replication in vitro. Viruses 13, 354.

Pawar, K.S., Mastud, R.N., Pawar, S.K., Pawar, S.S., Bhoite, R.R., Bhoite, R.R., Kulkarni, M.V., and Deshpande, A.R. 2021. Oral curcumin with piperine as adjuvant therapy for the treatment of COVID-19: a randomized clinical trial. Front. Pharmacol. 12, 669362.

Perveen, S. 2021. Introductory chapter: terpenes and terpenoids. IntechOpen, doi: 10.5772/intechopen.79683. Available from: https:// www.intechopen.com/chapters/62573.

Pillon, M.C., Frazier, M.N., Dillard, L.B., Williams, J.G., Kocaman, S., Krahn, J.M., Perera, L., Hayne, C.K., Gordon, J., Stewart, Z.D., et al. 2021. Cryo-EM structures of the SARS-CoV-2 endoribonuclease Nsp15 reveal insight into nuclease specificity and dynamics. Nat. Commun. 12, 636.

Pitsillou, E., Liang, J., Karagiannis, C., Ververis, K., Darmawan, K.K., Ng, K., Hung, A., and Karagiannis, T.C. 2020a. Interaction of small molecules with the SARS-CoV-2 main protease in silico and in vitro validation of potential lead compounds using an enzymelinked immunosorbent assay. Comput. Biol. Chem. 89, 107408.

Pitsillou, E., Liang, J., Ververis, K., Lim, K.W., Hung, A., and Karagiannis, T.C. 2020b. Identification of small molecule inhibitors of the deubiquitinating activity of the SARS-CoV-2 papain-like protease: in silico molecular docking studies and in vitro enzymatic activity assay. Front. Chem. 8, 623971.

Pizzorno, A., Padey, B., Dubois, J., Julien, T., Traversier, A., Dulière, V., Brun, P., Lina, B., Rosa-Calatrava, M., and Terrier, O. 2020. In vitro evaluation of antiviral activity of single and combined repurposable drugs against SARS-CoV-2. Antiviral Res. 181, 104878.

Rahman, H.S., Othman, H.H., Hammadi, N.I., Yeap, S.K., Amin, K.M., Abdul Samad, N., and Alitheen, N.B. 2020. Novel drug delivery systems for loading of natural plant extracts and their biomedical applications. Int. J. Nanomedicine 15, 2439-2483.

Salas Rojas, M., Silva Garcia, R., Bini, E., Pérez De La Cruz, V., León Contreras, J.C., Hernández Pando, R., Bastida Gonzalez, F., DavilaGonzalez, E., Orozco Morales, M., Gamboa Domínguez, A., et al. 2021. Quinacrine, an antimalarial drug with strong activity inhibiting SARS-CoV-2 viral replication in vitro. Viruses 13, 121.

Sa-Ngiamsuntorn, K., Suksatu, A., Pewkliang, Y., Thongsri, P., Kanjanasirirat, P., Manopwisedjaroen, S., Charoensutthivarakul, S., Wongtrakoongate, P., Pitiporn, S., Chaopreecha, J., et al. 2021. Anti-SARS-CoV-2 activity of Andrographis paniculata extract and its major component andrographolide in human lung epithelial cells and cytotoxicity evaluation in major organ cell representatives. J. Nat. Prod. 84, 1261-1270.

Santos, E.L., Sales Maia, B.H.L.N., Ferriani, A.P., and Teixeira, S.D. 2017. Flavonoids: classification, biosynthesis and chemical ecology. IntechOpen, DOI: 10.5772/67861. Available from: https:// www.intechopen.com/chapters/54574.

Shi, T.H., Huang, Y.L., Chen, C.C., Pi, W.C., Hsu, Y.L., Lo, L.C., Chen, W.Y., Fu, S.L., and Lin, C.H. 2020. Andrographolide and its fluorescent derivative inhibit the main proteases of 2019$\mathrm{nCoV}$ and SARS-CoV through covalent linkage. Biochem. Biophys. Res. Commun. 533, 467-473.
Song, J., Zhang, L., Xu, Y., Yang, D., Zhang, L., Yang, S., Zhang, W., Wang, J., Tian, S., Yang, S., et al. 2021. The comprehensive study on the therapeutic effects of baicalein for the treatment of COVID19 in vivo and in vitro. Biochem. Pharmacol. 183, 114302.

Stefanik, M., Strakova, P., Haviernik, J., Miller, A.D., Ruzek, D., and Eyer, L. 2021. Antiviral activity of vacuolar ATPase blocker diphyllin against SARS-CoV-2. Microorganisms 9, 471.

Su, H.X., Yao, S., Zhao, W.F., Li, M.J., Liu, J., Shang, W.J., Xie, H., Ke, C.Q., Hu, H.C., Gao, M.N., et al. 2020. Anti-SARS-CoV-2 activities in vitro of Shuanghuanglian preparations and bioactive ingredients. Acta Pharmacol. Sin. 41, 1167-1177.

ter Ellen, B.M., Dinesh Kumar, N., Bouma, E.M., Troost, B., Van De Pol, D.P.I., Van Der Ende-Metselaar, H.H., Apperloo, L., Van Gosliga, D., Van Den Berge, M., Nawijn, M.C., et al. 2021. Resveratrol and pterostilbene inhibit SARS-CoV-2 replication in air-liquid interface cultured human primary bronchial epithelial cells. Viruses 13, 1335.

The RECOVERY Collaborative Group. 2021. Dexamethasone in hospitalized patients with Covid-19. N. Engl. J. Med. 384, 693-704.

Tito, A., Colantuono, A., Pirone, L., Pedone, E., Intartaglia, D., Giamundo, G., Conte, I., Vitaglione, P., and Apone, F. 2021. Pomegranate peel extract as an inhibitor of SARS-CoV-2 spike binding to human ACE2 receptor (in vitro): a promising source of novel antiviral drugs. Front. Chem. 9, 231.

Tompa, D.R., Immanuel, A., Srikanth, S., and Kadhirvel, S. 2021. Trends and strategies to combat viral infections: a review on FDA approved antiviral drugs. Int. J. Biol. Macromol. 172, 524-541.

V'kovski, P., Kratzel, A., Steiner, S., Stalder, H., and Thiel, V. 2021. Coronavirus biology and replication: implications for SARSCoV-2. Nat. Rev. Microbiol. 19, 155-170.

Valizadeh, H., Abdolmohammadi-Vahid, S., Danshina, S., Ziya Gencer, M., Ammari, A., Sadeghi, A., Roshangar, L., Aslani, S., Esmaeilzadeh, A., Ghaebi, M., et al. 2020. Nano-curcumin therapy, a promising method in modulating inflammatory cytokines in COVID-19 patients. Int. Immunopharmacol. 89, 107088.

van de Sand, L., Bormann, M., Alt, M., Schipper, L., Heilingloh, C.S., Steinmann, E., Todt, D., Dittmer, U., Elsner, C., Witzke, O., et al. 2021. Glycyrrhizin effectively inhibits SARS-CoV-2 replication by inhibiting the viral main protease. Viruses 13, 609.

Varghese, F., Van Woudenbergh, E., Overheul, G., Eleveld, M., Kurver, L., Van Heerbeek, N., Van Laarhoven, A., Miesen, P., Den Hartog, G., De Jonge, M., et al. 2021. Berberine and obatoclax inhibit SARS-CoV-2 replication in primary human nasal epithelial cells in vitro. Viruses 13, 282.

Wang, S.C., Chen, Y., Wang, Y.C., Wang, W.J., Yang, C.S., Tsai, C.L., Hou, M.H., Chen, H.F., Shen, Y.C., and Hung, M.C. 2020a. Tannic acid suppresses SARS-CoV-2 as a dual inhibitor of the viral main protease and the cellular TMPRSS2 protease. Am. J. Cancer Res. 10, 4538-4546.

Wang, A., Sun, Y., Liu, Q., Wu, H., Liu, J., He, J., Yu, J., Chen, Q.Q., Ge, Y., Zhang, Z., et al. 2020b. Low dose of emetine as potential anti-SARS-CoV-2 virus therapy: preclinical in vitro inhibition and in vivo pharmacokinetic evidences. Mol. Biomed. 1, 14.

WHO, World Health Organization. 2020. WHO Coronavirus (COVID19) Dashboard. Available at: https://covid19.who.int.

Xia, B., Shen, X., He, Y., Pan, X., Liu, F.L., Wang, Y., Yang, F., Fang, S., Wu, Y., Duan, Z., et al. 2021. SARS-CoV-2 envelope protein causes acute respiratory distress syndrome (ARDS)-like pathological damages and constitutes an antiviral target. Cell Res. 31, 847-860.

Xu, J., Xu, Z., and Zheng, W. 2017. A review of the antiviral role of green tea catechins. Molecules 22, 1337.

Yan, R., Zhang, Y., Li, Y., Xia, L., Guo, Y., and Zhou, Q. 2020. Structural basis for the recognition of SARS-CoV-2 by full-length human ACE2. Science 367, 1444-1448.

Yang, C.W., Lee, Y.Z., Hsu, H.Y., Jan, J.T., Lin, Y.L., Chang, S.Y., Peng, T.T., Yang, R.B., Liang, J.J., Liao, C.C., et al. 2020. Inhibition of 
SARS-CoV-2 by highly potent broad-spectrum anti-coronaviral tylophorine-based derivatives. Front. Pharmacol. 11, 606097.

Yang, M., Wei, J., Huang, T., Lei, L., Shen, C., Lai, J., Yang, M., Liu, L., Yang, Y., Liu, G., et al. 2021a. Resveratrol inhibits the replication of severe acute respiratory syndrome coronavirus 2 (SARSCoV-2) in cultured Vero cells. Phytother. Res. 35, 1127-1129.

Yang, S., Xu, M., Lee, E.M., Gorshkov, K., Shiryaev, S.A., He, S., Sun, W., Cheng, Y.S., Hu, X., Tharappel, A.M., et al. 2018. Emetine inhibits Zika and Ebola virus infections through two molecular mechanisms: inhibiting viral replication and decreasing viral entry. Cell Discov. 4, 31.

Yang, Y., Yang, P., Huang, C., Wu, Y., Zhou, Z., Wang, X, and Wang, S. 2021b. Inhibitory effect on SARS-CoV-2 infection of neferine by blocking $\mathrm{Ca}^{2+}$-dependent membrane fusion. J. Med. Virol.
93, 5825-5832.

Zhan, Y., Ta, W., Tang, W., Hua, R., Wang, J., Wang, C., and Lu, W. 2021. Potential antiviral activity of isorhamnetin against SARSCoV-2 spike pseudotyped virus in vitro. Drug Dev. Res. doi: $10.1002 /$ ddr.21815.

Zhang, Y.N., Zhang, Q.Y., Li, X.D., Xiong, J., Xiao, S.Q., Wang, Z., Zhang, Z.R., Deng, C.L., Yang, X.L., Wei, H.P., et al. 2020. Gemcitabine, lycorine and oxysophoridine inhibit novel coronavirus (SARS-CoV-2) in cell culture. Emerg. Microbes Infect. 9, 11701173.

Zhao, Y., Du, X., Duan, Y., Pan, X., Sun, Y., You, T., Han, L., Jin, Z., Shang, W., Yu, J., et al. 2021. High-throughput screening identifies established drugs as SARS-CoV-2 PL ${ }^{\text {pro }}$ inhibitors. Protein Cell 1-12. doi:10.1007/s13238-021-00836-9. 